\title{
Cosmin Pricop
}

\section{Die Verwandlung Jesu Christi}

\author{
Historisch-kritische und patristische Studien
}

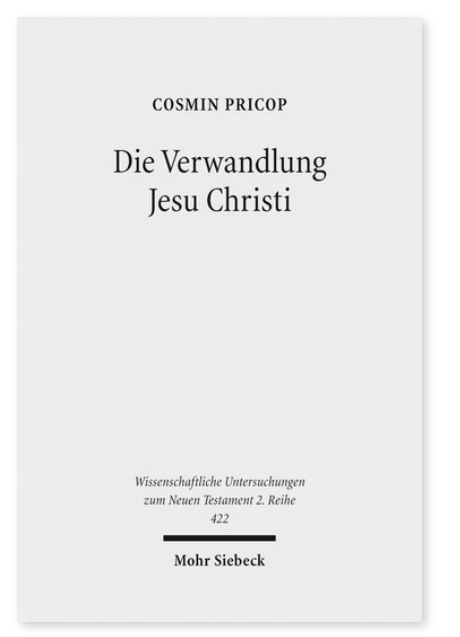

2016. XVIII, 378 Seiten. WUNT II 422

ISBN 978-3-16-153696-0

DOI 10.1628/978-3-16-153696-0

eBook PDF $114,00 €$

ISBN 978-3-16-153695-3

fadengeheftete Broschur 114,00€
Die gegenwärtige orthodoxe Exegese ist noch immer fast ausschließlich von der Wiedergabe patristischer Bibelauslegungen und ihrer Hermeneutik geprägt, während die westliche Exegese seit der Aufklärung einen tiefgreifenden hermeneutischen Reflexionsprozess durchlaufen und ein entsprechendes methodisches Instrumentarium entwickelt hat. Was für die orthodoxe Exegese typisch ist, wird von akademischer westlicher Exegese als unzureichend empfunden und vice versa. In seiner Untersuchung wirft Cosmin Pricop die Frage auf, wie sich diese Herangehensweisen gegenseitig bereichern können. Er korreliert patristische Bibelauslegung mit wissenschaftlichen Methoden westlicher Exegese am Beispiel der Verwandlungserzählung und zeigt auf, wie sie sich wechselseitig ergänzen können. Im Horizont dieser Perspektiven ist Pricops Studie als ökumenischer Beitrag konzipiert.

Die Arbeit wurde von der Kurt-Hellmich-Stiftung in Regensburg mit dem zweiten Preis zur Würdigung hervorragender wissenschaftlicher Arbeiten und Leistungen auf dem Gebiet der ökumenischen Theologie ausgezeichnet.

Cosmin Pricop Geboren 1981; Studium der Orthodoxen und Ev. Theologie; 2007 MA; 2010 erste Promotion in Rumänien; 2014 zweite Promotion in Deutschland; seit 2011 Assistent im Fach Neues Testament an der Orth.-Theol. Fakultät der Universität Bukarest; seit 2011 Diakon in der Bukarester Gemeinde Delea-Noua.
Jetzt bestellen:

https://mohrsiebeck.com/buch/die-verwandlung-jesu-christi-9783161536960?no_cache=1

order@mohrsiebeck.com

Telefon: $+49(0) 7071-923-17$

Telefax: $+49(0) 7071-51104$ 